\title{
Chapter 21 \\ Age Verification of Three Japanese Supercentenarians Who Reached Age 115
}

\author{
Yasuyuki Gondo, Nobuyoshi Hirose, Saori Yasumoto, Yoshiko Lily Ishioka, \\ Hiroki Inagaki, Yukie Masui, Yasumichi Arai, and Yasuhiko Saito
}

Compared to other countries, Japan is the world leader in longevity and has the largest proportion of centenarians par total population. According to Japan's Ministry of Health, Labor and Welfare, the number of centenarians living in the country as of September 2017 was 67,824. However, there are only eight known cases in Japan of individuals surviving to age 115 (Table 21.1). This chapter presents the life histories of three Japanese supercentenarians who lived more than 115 years, and provides details of the age verification processes used to confirm their ages. The first case is that of Mr. Jiroemon Kimura (J.K.), who was the longest-lived man in the world. He passed away in June 12, 2013, at the age of 116 years and 54 days. The second case is that of Mrs. Misao Okawa (M.O.), who was the first Japanese person to reach the age of 117 years. She passed away on April 1, 2015, at the age of 117 years and 27 days. The third case is that of Mrs. Chiyo Miyako (C.M.), who was alive at the age of 117 years when We wrote this chapter in June 11, 2018. She was ranked as the oldest living person in the world after Mrs. Nabi Tajima (117 years and 260 days

\footnotetext{
Y. Gondo $(\varangle) \cdot S$. Yasumoto

Graduate School of Human Science, Osaka University, Osaka, Japan

e-mail:ygondo@hus.osaka-u.ac.jp; syasumoto@hus.osaka-u.ac.jp

N. Hirose · Y. Arai

Center for Supercentenarian Medical Research, Keio University School of Medicine,

Tokyo, Japan

e-mail: nobu.hirose1609@gmail.com; yasumich@keio.jp

Y. L. Ishioka

Graduate School of Science and Technology, Keio University, Kanagawa, Japan

e-mail: lily@keio.jp

H. Inagaki · Y. Masui

Tokyo Metropolitan Institute of Gerontology, Tokyo, Japan

Y. Saito

Nihon University, Tokyo, Japan

e-mail: saito.yasuhiko@nihon-u.ac.jp
} 
Table 21.1 List of Japanese supercentenarians who reached age 115 years (as of July 23, 2018)

\begin{tabular}{l|l|l|l|l|c}
\hline Number & Name & Born & Died & Years & Days \\
\hline 1. & Tane Ikai & January 18, 1879 & July 12, 1995 & 116 & 175 \\
\hline 2. & Chiyono Hasegawa & November 20, 1896 & December 2, 2011 & 115 & 12 \\
\hline 3. & Jiroemon Kimura & April 19, 1897 & June 12, 2013 & 116 & 54 \\
\hline 4. & Koto Okubo & December 24, 1897 & January 12, 2013 & 115 & 19 \\
\hline 5. & Misao Okawa & March 5, 1898 & April 1, 2015 & 117 & 27 \\
\hline 6. & Nabi Tajima & August 4, 1900 & April 21, 2018 & 117 & 260 \\
\hline 7. & Chiyo Miyako & May 2, 1901 & July 22, 2018 & 117 & 81 \\
\hline 8. & N.A. (anonymous) & March 15, 1900 & September 27, 2015 & 115 & 196 \\
\hline
\end{tabular}

old), who considered the longest-lived Japanese person. Regretfully, we were unable to contact Mrs. Tajima.

\subsection{Data Sources Available for the Age Verification of the Oldest-Old in Japan}

The data sources that can be used in Japan to verify a person's age may be categorized as official administrative data or non-official data. The official data are issued and maintained by governmental authorities. For example, school systems may keep records that refer to their former pupils, while companies may keep records that refer to their former employees. The non-official data sources include stories told by family members and acquaintances, as well as media reports.

\subsubsection{Official Data}

\subsubsection{Administrative Data Sources}

The KOSEKI (the Family Register) and the JUMIN-KIHON-DAICHO (the Resident Registry) are the primary sources used for age verification in Japan. The KOSEKI is based on the registered residence of the family, whereas the JUMINKIHON-DAICHO is based on the current place of residence, which is in turn linked to the Family Register. When all of the family members have moved out the family's residence due to marriage or death, the family's KOSEKI is relabeled JYOSEKI and is placed in storage. The Japanese system of KOSEKI was first established in 1872. Evaluations of the first few decades of the records have shown that the data are unreliable. With regard to the ages of centenarians, any records issued since 1972 are considered reliable (Wilmoth and Lundstrom 1996). The faulty registration of age is much less likely to occur among newborns than among people who are reporting their age while in their sixties or seventies. However, even though 
this system is relatively reliable, centenarians were misidentified using the data from these registers in 2010 (Saito et al. 2012). This occurred mainly because deaths recorded in the Resident Registry were not transferred to the Family Register. There were even some cases in which family members intentionally avoided reporting the deaths of centenarians in order to receive pension money from the government. Local governments finally discovered these cases by conducting face-to-face interviews with registered centenarians.

The ZENKOKU KOUREISHA MEIBO (the list of oldest-old survivors in Japan) was published for a short period of time only (until 2003) by Japan's Ministry of Health, Labor and Welfare. The list was compiled based on the JUMIN-KIHONDAICHO for the purpose of identifying centenarians for sending award of celebrating longevity by the Japanese prime minster. As the lists had been semi-open to the public, we used them to identify centenarians.

\subsubsection{Data Sources Related to Education and Employment}

Documents Related to Education are also useful sources for verifying age. Because almost $100 \%$ of Japanese children were enrolled in primary school in 1905, the likelihood of being able to find the name of a particular graduate in the graduation lists is high. In addition, some elementary schools have published a book celebrating the 100-year anniversary of the school's founding in which the names of past graduates are published.

Employment Records can include information on the work-related records of former employees. If an organization that employed a centenarian still exists today, the employment records of the individual may be available for age verification.

\subsubsection{Non-official Data Sources}

Among the non-official data sources that can be used in the age validation process are the centenarian's personal memories, the testimonies of his/her relatives, a diary or an autobiography written by the centenarian, and media reports. As the reliability of these data is lower than that of data from official sources, the accuracy of the information extracted from non-official data sources must be double-checked using a third source, such as the records of historical events. Checking whether stories that have been told/written by/about the centenarian are consistent with historical records can help us avoid misidentifying a person. 


\subsection{Age Verification of Three Supercentenarians}

As participants in the Tokyo centenarian study and Japanese semi-supercentenarian study (Arai et al. 2014), the first (Y.G.), second (N.H.), fourth (H.I.), and fifth authors (Y.M.) of this article have conducted face-to-face interviews with the three supercentenarians when they were centenarians, and with their family members. In the following sections, we describe the life histories of the three supercentenarians along with the sources we used to verify the person's age in each case.

\subsubsection{CASE 1: Jiroemon Kimura (J.K)}

We have previously published an article in which we explained how we verified the age of J.K (Gondo et al. 2017). Thus, in the following, we will provide only a brief summary of the age verification process in his case, and will instead focus on describing his life experiences.

\subsubsection{Description of the Age Verification Sources}

Because J.K. lived in the same village most of his life, we were able to draw from a variety of sources to verify his age. The official records consist of the JYOSEKI of the original family (Fig. 21.1), the KOSEKI of the family he married into (Fig. 21.2), the JUMIN-KIHON-DAICHO (Fig. 21.3), the original graduation list of the local elementary school (refer to Gondo et al. 2017), the centenary anniversary history book of the local elementary school (refer to Gondo et al., 2017), and the official employment record of J.K. from Japan's Ministry of Posts and Telecommunications. The non-official records consist of a booklet about J.K.'s life published when he was 105 years old, a newspaper interview with J.K. about his old friend, and information from an interview of J.K. by the authors (Y.G. and N.H.).

\subsubsection{The Life History of J.K}

J.K. was born on April 19, 1897, in Kami-Ukawa village, Takeno-gun, in the Kyoto prefecture. He was the fifth of eight children of a farming couple, the Miyake family. The structure of his original family could be confirmed by the JYOSEKI (Fig. 21.1). His original name was Kinjiro Miyake. He graduated from higher elementary school on March 31, 1911. While J.K.'s birthday was reported as a date in March in the graduation list, we found that his birthday was reported as a date in April in the official government documents (JYOSEKI, KOSEKI, and KIHON DAICHO). His nephew told us that J.K. believed that his correct date of birth was 1 month earlier than the date reported in the official record. We speculated that his 


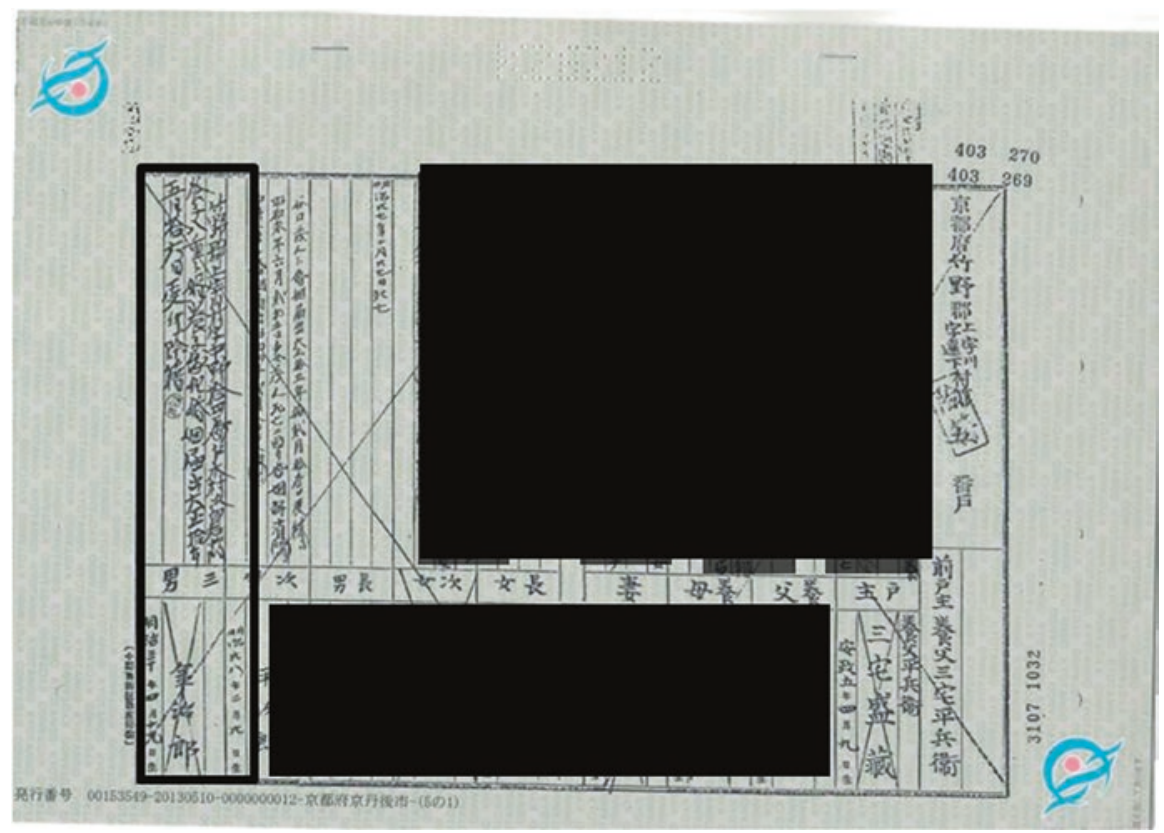

Fig. 21.1 Jyoseki Tohon of the original family (Miyake). J.K.'s old name (Kinjiro) and his history are written in the area surrounded by the black box

parents had wanted him to join the labor force as soon as possible so he could earn money to help the impoverished household, and that they therefore reported a March birth date for J.K. that would allow him to start schooling 1 year earlier. This was a relatively common practice in rural areas in Japan at that time. Thus, we concluded that his correct birthday is April 19, 1897 (Gondo et al. 2017).

After graduation, J.K. took a position as a telegram delivery person. He also held various other post office-related jobs over the course of his career. Except for a short period that he spent as a sake brewer in Nara prefecture, and a period that he spent as a farmer after retirement, his employment history could be confirmed by consulting the official employment records issued by Japan's Ministry of Posts and Telecommunications. He attended a special school in Kyoto city to acquire skills related to mail and telegram delivery from May to November in 1914. He then started working in the local post office (Nakahama post office). On May 31, 1920, he moved to occupied Korea to take care of his sick younger brother for 5 months. During that period, he also worked at the Bureau of Telecommunications in Korea.

On December 27, 1920, he returned to his home village and married Yae Kimura. On their wedding day, J.K. was 23 years old and Yae was 18 years old. After marrying into the Kimura family, he was recognized as the successor of Jiroemon Kimura the 8th. He had six sons and two daughters. The first child was born in 1922, when he was 25 years old, and the last child was born in 1943, when he was 46 years old. He officially inherited and changed his name from Kinjiro Kimura to Jiroemon 


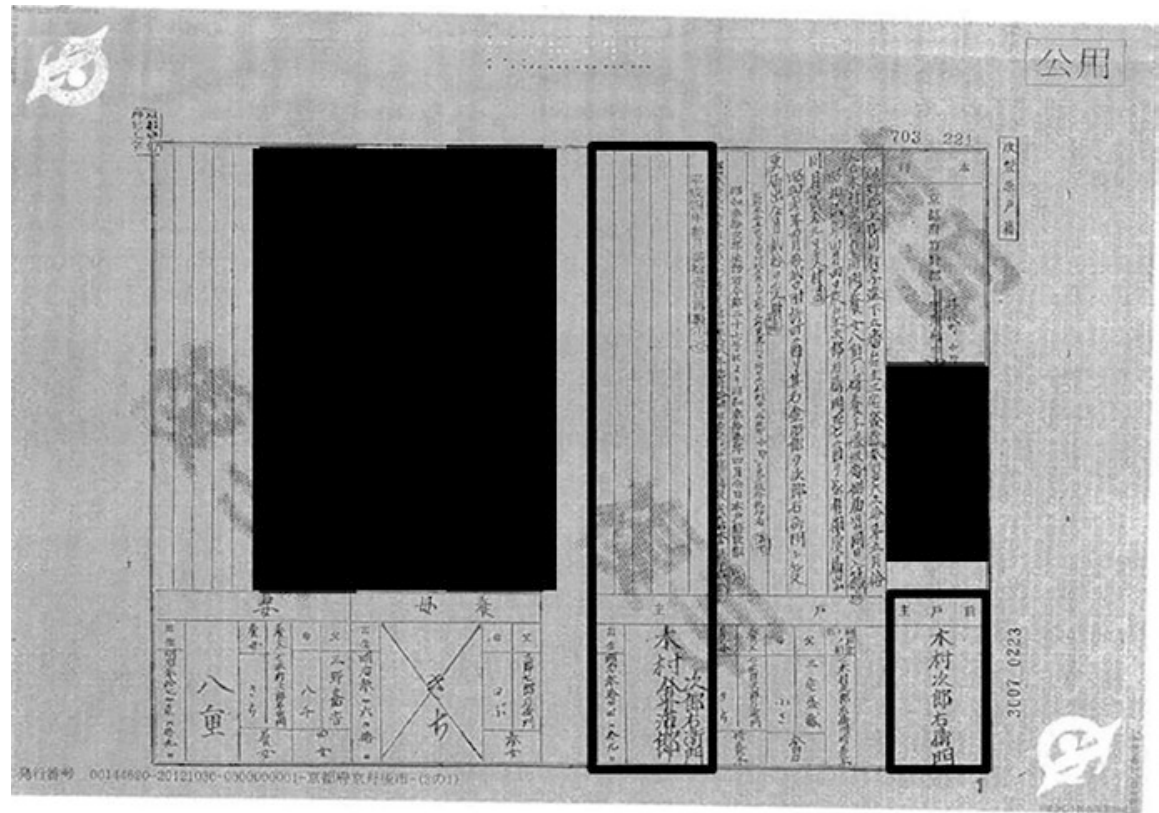

Fig. 21.2 Koseki Tohon of the original family. J.K.'s old name and new name (9th), which is the same as that of the head of the family he married into, is written in parallel (larger box). The same name (8th) is written on the left as a head of the family (small box). The old name is corrected by strike-through (larger box, left name)

Kimura after the death of his father-in-law on April 4, 1927. He started working at the small Hira post office on April 21, 1924, and he remained there until his retirement. According to the job records, he had served as a communication soldier twice for short periods of time in 1919 and 1921.

He retired from the post office on June 30, 1962. In 1963, he built a new house. He was very proud that he was able to build a new house using his retirement bonuses. For the rest of his life, until reached his early one-hundreds, he worked as a part-time farmer helping his son. In 1978, J.K. and his wife started living in the house with their first son's family and their first grandson's family. At its largest, including J.K.'s son's and grandson's family, he lived with nine family members. His wife passed away in 1979 when he was 82 years old.

In 1981, the Kimura family had a family reunion to celebrate 500 years of life, which was the sum of the ages of J.K. and his siblings (Fig. 21.4). On December 11, 1999, a well-known national TV program that covers Japan's local communities and their cultural activities invited J.K. to appear as a guest. Because of this TV appearance, J.K. became popular nationwide. He reported having received hundreds of letters.

J.K.'s first son passed away in 2000 at the age of 76 . He expressed his sorrow that his son died before him in the booklet entitled "Looking back on my happy 105 


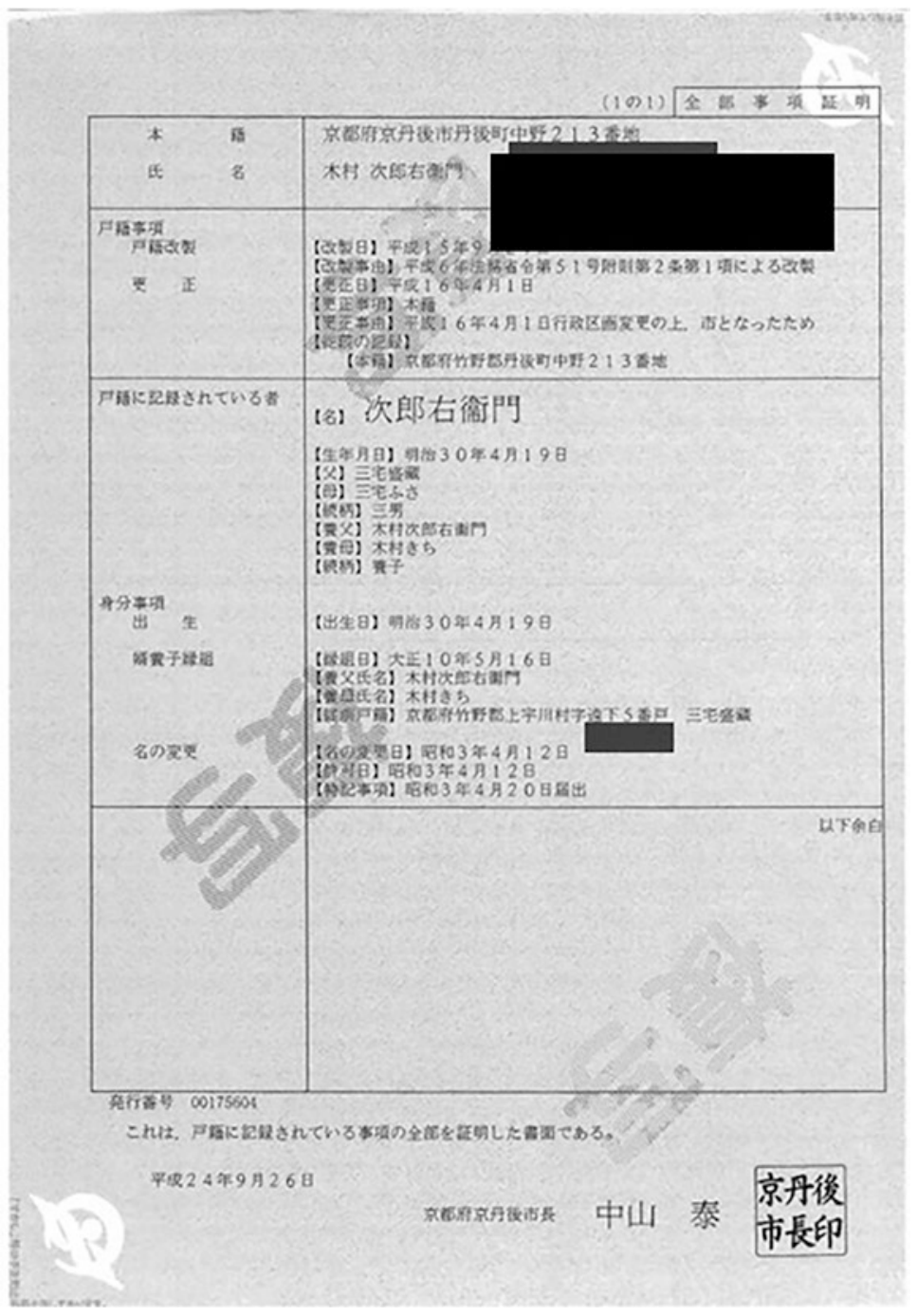

Fig. 21.3 Zenbu Kisai Shomei of J.K

years," published in 2002 (Kimura 2002). He also lost his grandson in 2005 at the age of 52 . He then lived with his daughter-in-law and granddaughter-in-law.

J.K. participated in our Japanese semi-supercentenarian study in 2008 when he was 111 years old. The authors (Y.G and N.H.) visited him a total of six times between then and his death in 2013. At the first interview, he sat on the tatami floor without using any supportive device for more than an hour and a half, and told his life history clearly and energetically. He reported that he read newspapers every day and was careful with his diet. When we were about to leave his home, J.K. said in English: "Thank you very much. You are a very kind man." He loved to speak 


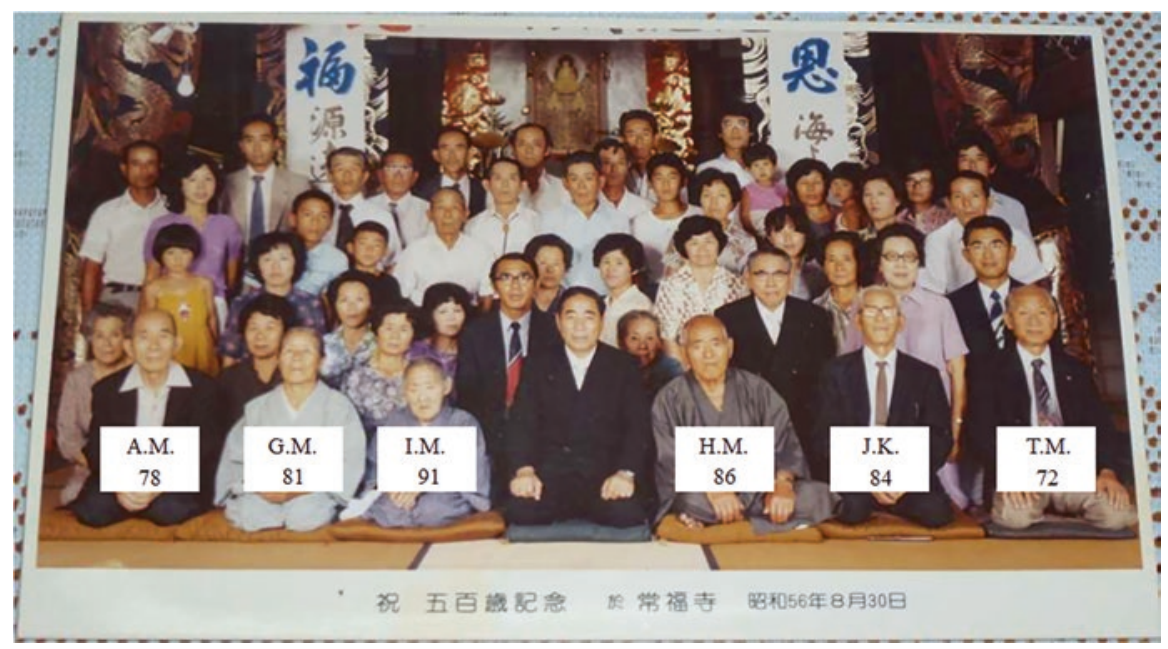

Fig. 21.4 Family picture taken in 1981 that was entitled "The Cerebration of 500 years old." In the first row, the six siblings, including J.K., and their ages are described by authors. The ages noted on the picture use the new Japanese age counting system in which people are counted as zero years old at birth, which means the total age of the siblings was 492 at the time the picture was taken. In the old Japanese age counting system, people were counted as 1 year old at birth. Under this system, the sum of the five siblings' ages is 498 . The picture was provided by Miyake Shinji, a nephew of J.K

English because he had learned English while he was studying at the special school for mail and telegram delivery in Kyoto. He recalled the name of the English textbook he used at the time as National Reader. Presumably, he was referring to Barnes' New National Readers, which has been the most widely used textbook for learning English in Japan since 1883. Because J.K. looked very healthy and fit, one of the authors (Y.G.) strongly doubted his age. We therefore decided to perform a study to verify his age.

J.K. again received attention from the media when he became the oldest living man in Japan at the age of 112 on June 19, 2009. Thereafter, he was introduced in the media as the oldest Japanese man on his birthdays and on Respect for Senior Citizens Day (the third Monday in September). He maintained good health until about 1 year before his death, and was cited as an example of a healthy supercentenarian in a NHK (a national network in Japan) documentary program in 2012. His daughter-in-law passed away in 2013 at the age of 83. In the final phase of his life, he lived with his granddaughter-in-law. We visited him for the last time on May 11, 2013, but we could not talk to him because he had been admitted to the hospital on that day after falling ill. J.K. passed away on June 12, 2013, at the age of 116 and 54 days.

J.K. had had raise a large family: by the time he reached the final phase of his life, he had eight children, 14 grandchildren, 25 great-grandchildren, and 14 greatgreat-grandchildren. One of the authors (Y.G.) met two of his offspring by chance. 
We can say with some confidence that J.K. lived a long and happy life, as he reported in his autobiography booklet.

\subsubsection{Case 2: Misao Okawa (M.O)}

M.O. is the first Japanese supercentenarian to reach the age of 117 . We visited her four times in total from 2013 to 2015 as part of our semi-supercentenarian study and for a newspaper interview. Although her son and the director of the special nursing home where she was living kindly provided us with many resources for verifying her age, we faced difficulties in obtaining some of the official governmental records on her life because of wartime damage and her frequent relocations.

\subsubsection{Description of Age Verification Sources}

Among the official documents we were able to collect for M.O. were her KOSEKI (Fig. 21.5) and a mention of her in the ZENKOKU KOUREISH MEIBO. Her KOSEKI (Fig. 21.5) shows that she became a family head after separating from the KOSEKI of her husband's family. Her name was on the ZENKOKU KOUREISH MEIBO, which is a list of people living in Japan who became centenarians. We also gathered documents from her nursing home. However, many of the official documents that refer to her life were lost during World War II. In addition, her frequent relocations made it difficult for us to track down the official records of her past. Among the non-official records, we were able to obtain several articles in newspapers and magazines about her and testimonies of her family members and the nursing home staff. We first met M.O. in 2013, but because she was already suffering from dementia, she was unable to provide us with further information.

\subsubsection{The Life History of M.O.}

M.O. was born on March 5, 1898, as the fourth child of the Aoki family. According to her son, M.O. was born in Temma district, which is located in the northern part of Osaka prefecture. Her family moved to Takarazuka city, which is a bedroom community in the Osaka prefecture. As her parents were the successful owners of a kimono fabric business, the family lived in a tri-level house and had a housekeeper. Her parents often took her downtown to buy fashionable clothes.

We tried to find the KOSEKI of M.O.'s original family to confirm her birthday, but were unsuccessful. M.O. established her own KOSEKI in 1951 (Fig. 21.5), and it is the primary source used to confirm her date of birth. We also attempted to find the graduation records of her elementary school. We contacted the board of education in Takarazuka city, Hyogo prefecture, because her son told us that when the family went to watch the Takarazuka Revue, M.O. took them to the house in 


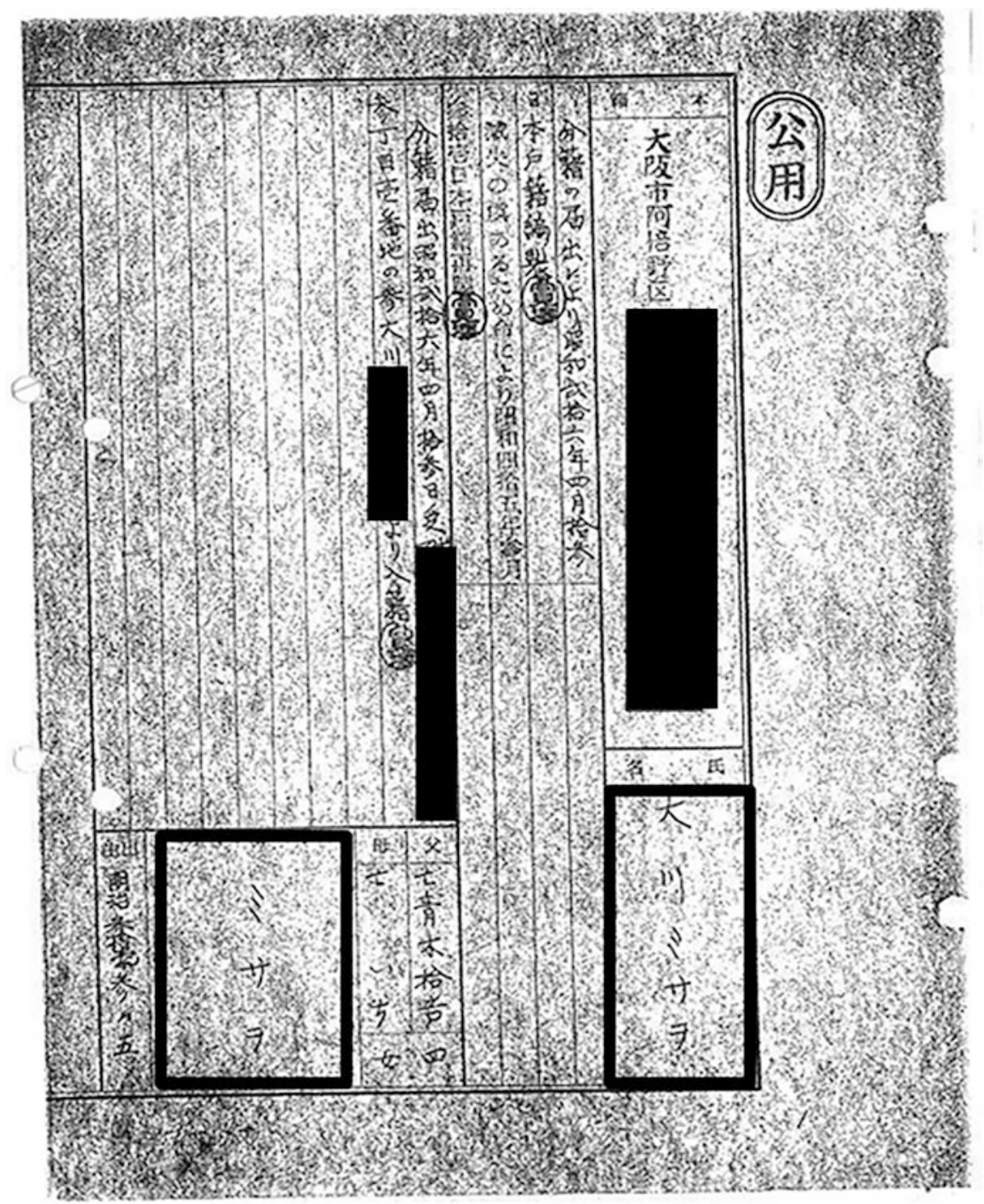

Fig. 21.5 Newly established Koseki of the family M.O. became the head of in 1951

Takarazuka city where she grew up. We could find the names of five schools established more than 100 years ago. Two of them, Nishitani and Ryogen elementary schools, have published an anniversary booklet with the list of graduates; however, we could not find her name on the lists. After M.O. graduated from elementary school, she helped her family with the housekeeping and Japanese dressmaking.

In 1919, when she was 21 years old, she married Yukio Okawa, who ran a rubber manufacturing company in Kobe city, Hyogo prefecture. He was successful in his business. They had three children: two daughters who were born in 1921 and 1926, 
and a son who was born in 1923. Their children's dates of birth were confirmed on the second and third pages of M.O.'s KOSEKI (Figure not shown). However, we could not confirm her date of marriage or the date of her husband's death because this information was recorded in the KOSEKI of her husband. M.O.'s husband was quite a modern man. He enjoyed drinking a cup of coffee and eating bread on Sundays, which was uncommon in those days. She loved the modern life style, and actively learned how to cook a variety of dishes, such as Chinese dishes and beefsteak. Her son remembers that the family used to go out to Chinatown in Kobe to eat Chinese food, and that his mother often asked the restaurant staff for their Chinese recipes. He also remembers seeing Chinese men with the queue hairstyle working in Chinatown during that period. In 1931, M.O.'s husband died of heart disease. Two years later, she went back to her parents' house in Sumiyoshi ward in Osaka city with her children. M.O. brought them up with help from her older sister, while running the transportation company.

Kansai region, where M.O. lived in the early 1990s, was the birthplace of popular culture in Japan because Osaka, Kobe, and Kyoto functioned as important centers of business and transportation. After the Great Kanto Earthquake of 1923 damaged Tokyo and the surrounding areas, many displaced people moved into Osaka city, making it the largest city in Japan. Private railway networks were established in Osaka in the late 1920s and the early 1930s - before such networks came to Tokyo. We assume that one of the reasons M.O.'s family moved from the center of Osaka city to Takarazuka city was the development of these railway networks. Railway lines connecting Osaka and Takarazuka started providing transportation services in 1897, or 1 year before M.O. was born. Moreover, Takarazuka city was the birthplace of the Takarazuka Revue, a famous act with an all-female cast that was started in 1914, and is still being performed today (http://kageki.hankyu.co.jp/ english/index.html). M.O.'s son recalls that she took her children from Kobe to watch the revue. It thus appears that M.O. enjoyed a modern city life as a member of a wealthy family.

We could not obtain information about M.O.s life in her forties, which coincided with WWII. In 1951, when she was 53 years old, M.O. established a new KOSEKI, which included her children (Fig. 21.5). According to this document, the registered address was changed from Fukiai ward in Kobe to Abeno ward in Osaka on April 13, 1951. This means that M.O. had been a member of husband's family for about 20 years after he died. We believe that the marriage of her second daughter in 1951 was the reason for the establishment of her new KOSEKI. M.O.'s first daughter and her son married in 1953 and 1956, respectively. After her first daughter's marriage, M.O. lived with her son, and later with his wife and children at the same place until she moved to a special nursing home in 1996.

According to her granddaughter, M.O. enjoyed watching professional wrestling, which was very popular on Japanese television in the 1970s. Although she underwent left femoral replacement surgery when she was 83 years old, she could still wear a kimono and walk by herself using a walking stick. Figure 21.6 shows a photo that was taken when M.O. was 98 years old. The occasion was a family reunion marking the renovation of her house in 1996. One year before this photo was taken, 


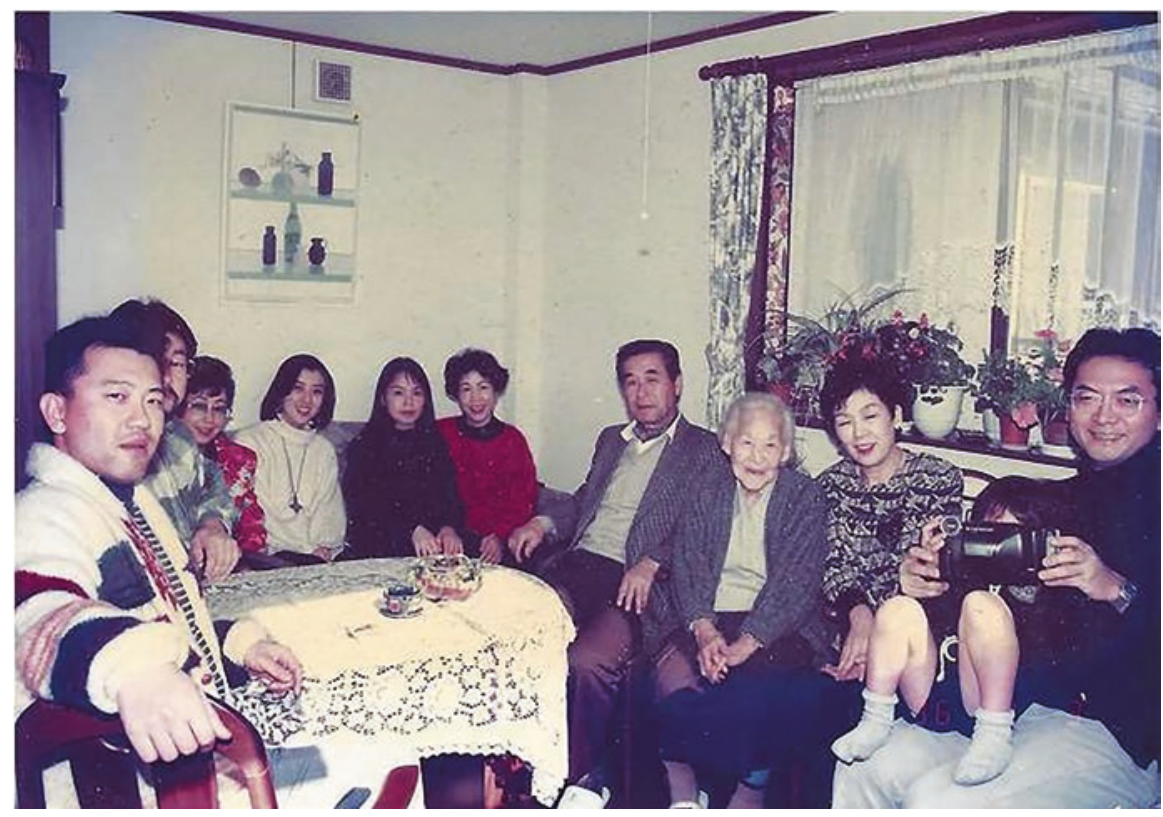

Fig. 21.6 M.O. at the age of 98 years surrounded by her family members at home

M.O. had a fall accident and underwent surgery to repair a femoral fracture. After this photo was taken, she started complaining of unbearable generalized pain and lost her appetite. Soon after, she was hospitalized. "She was on the verge of death," her son recalled. Miraculously, she was released from the pain through a single injection to her hip at the pain clinic. Although M.O. recovered from this acute condition, the experience led her 74-year-old son and his wife to reconsider taking care of M.O. at home.

On January 1, 1997, at the age of 98, M.O. moved to a special nursing home for older adults, where she stayed until her final days. Although she used a walking stick, she still wore a kimono and walked by herself. She had no major diseases and no symptoms of dementia at that time. Her only complaint was occasional constipation. The basic activities of daily living (BADLs) she was still able to perform were sufficient to allow her to take care of herself as a nursing home resident. At that time, her doctor commented in her care facility record: "I envy her health condition."

According to reports, M.O. had a strong will and retained her curiosity even after reaching the age of 100 . At the age 102, she fractured her femur again when she was dancing at the Bon Festival. After leaving the hospital, she voluntarily underwent rehabilitation and regained her walking ability. She continued to knit until she was around 105 years old. When she was 109 years old, she walked a 70-meter-long corridor 10-20 times per day using a walking stick or pushing a wheelchair by herself. 
On August 1, 2013, M.O. became the world's longest-living person. At that point, she started getting media attention. She told reporters that she did not pay special attention to her health, and had not been living a healthy lifestyle. She did not stop smoking until she was about 70 years old. However, she also told the media that having a good appetite and being easygoing are the secrets to longevity. Her hobby was making and designing new styles of kimono. She was cheerful, social, and optimistic. She always responded in interviews with cheerful comments. One of the authors (Y.G.) visited M.O. as she was being interviewed by a newspaper on May 13, 2013. At that time, she was severely demented, and it was difficult to communicate with her. But when Y.G. asked her whether she was happy, she replied "So-so happy." When he asked her, "Will I also become happy if I imitate your lifestyle?" she answered, "It will not go as smoothly as you think." On March 5, 2015, M.O. became the first Japanese person to reach the age of 117. She passed away on April 1, 2015, at the age of 117 and 27 days.

To verify her age, we were only able to obtain a few government registry-related documents (KOSEKI and JYUMIN-KIHON-DAICH and ZENKOKU KOUREISHA MEIBO). However, we found no inconsistencies among the testimonies provided by her relatives or herself. It is important to note that two of her children are still alive. M.O.'s first daughter was 95 years old and her son was 93 years old when she died. Her long-living children may be the best evidence that M.O. had a very long life. Based on the multiple sources of information about M.O.'s life we have described in this article, we can conclude that she was the first Japanese person to reach the age of 117 .

\subsubsection{CASE 3: Chiyo Miyako (C.M)}

As the final case, we introduce C.M., who participated in both the Tokyo centenarian study (Gondo et al. 2006) and the Japanese semi-supercentenarian study (Arai et al. 2014). She is the last survivor among the participants. She became the longestliving person in Japan on April 21, 2018.

\subsubsection{Description of Age Verification Sources}

We collected information on C.M. from her KOSEKI (Fig. 21.7), the JUMINKIHON-DAICHO, and the ZENKOKU KOUREISHA MEIBO. Her name was on the residential list Minato ward provided us with when we were preparing invitations to prospective participants in the Tokyo centenarian study in 1999. Moreover, C.M.'s life history was published as a chapter of the centenarian life study book HYAKUSAI HYAKUWA (Centenarian research group, 2003); which in English means "a hundred stories from centenarians." We have checked the consistency and accuracy of her stories by comparing them with actual historical events. She is now living in a nursing home, which her grandson is managing. 


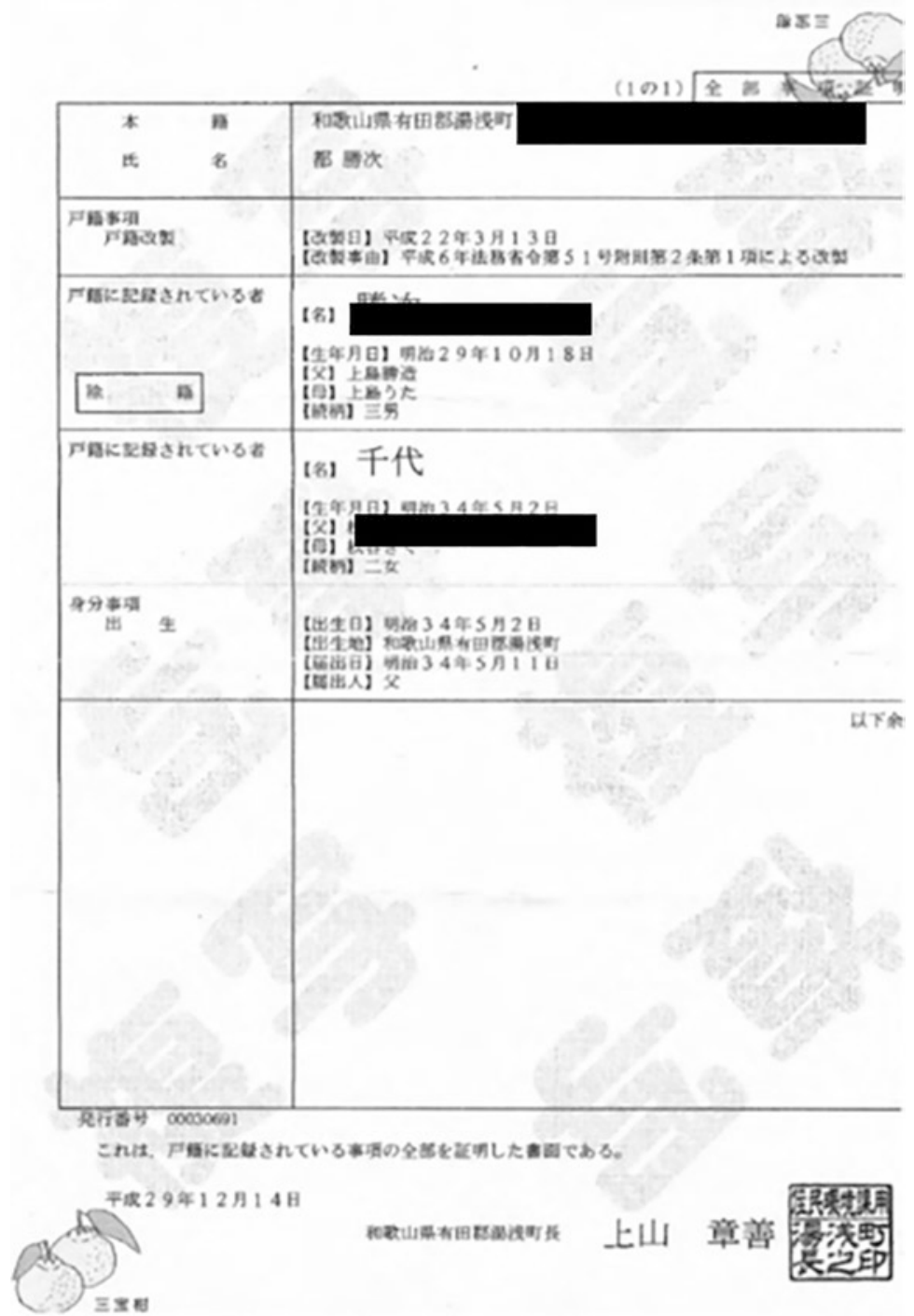

Fig. 21.7 Zenbu Kisai Shomei of C.M. A computerized Koseki

\subsubsection{The Life History of C.M}

C.M. was born on May 2, 1901, in Yuasa town in Wakayama prefecture, which is famous for growing mandarin oranges. Her parents owned a wholesale paper store. She was born as the fourth of five children, but she grew up as a first child of her parents because her older siblings all died at early ages. She had one younger brother. When she was younger, she enjoyed her lessons at school, except for 
physical education. After finishing elementary school, she attended a school for girls in Wakayama prefecture. After graduating from the girls' school, she pursued further education at the telegraph school in Osaka. While she was studying in Osaka, she met a tall, nice-looking man named Katsuji Miyako in her apartment building. They got along well, and soon fell in love. When C.M. wrote a letter to her suitor, he responded by writing her two or three letters. He had a reputation for being fashionable, and was said to have been as handsome as an American movie star. Mr. Miyako was a student at Kyoto University, which is one of the most prestigious universities in Japan. Because of his status as a student, the couple had a family wedding without publically announcing their marriage. Interestingly, the story of the marriage has changed over time. The abovementioned story was told by C.M. during an interview in 2016 involving one of the authors (N.H.). However, when the author (Y.M.) had interviewed C.M. for the centenarians' story book in 2002, she said that her wedding was arranged by her parents, and that she and her husband were not romantically attracted to each other at the beginning of their marriage. We believe that the couple actually fell in love, but that C.M. had been embarrassed to tell us the real story the first time because a love-based marriage was not common for her generation. A picture taken around the time of their wedding reveals the truth (Fig. 21.8). We should also add that the couple appear to have had a happy

Fig. 21.8 C.M. and her husband in their newly married days

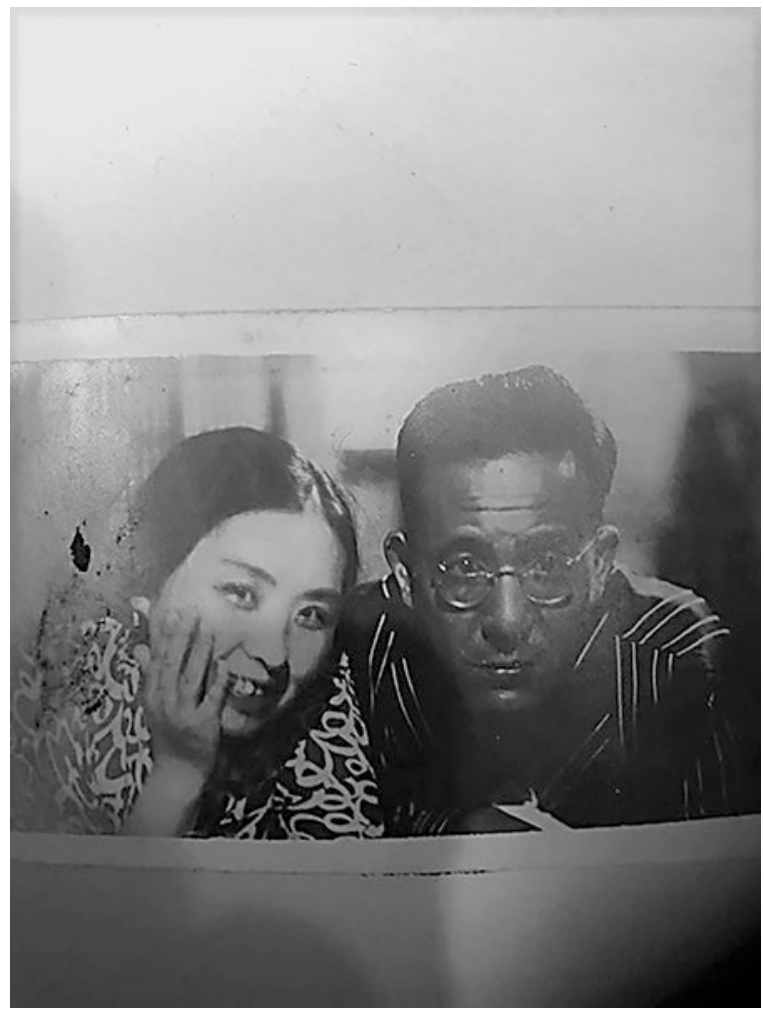


marriage. According to C.M., "It was a good match and we had a wonderful marital life."

After marrying, C.M. started working as an operator at the Central Telecommunications Bureau located in Osaka. In those days, not many women participated in the labor force. In fact, she was the only female employee in her branch. Meanwhile, her husband was employed by the Ministry of Railways, and had to undertake many overseas business trips to perform inspections. The longest separation the couple experienced was when Mr. Miyako was overseas for 2 years as part of his education. Soon after he returned to Japan, the couple started having children: a son was born in 1922, and a daughter was born in 1927. Because of Mr. Miyako's job, the family relocated a few times. For C.M., Beijing was the most memorable place. One year after moving to Beijing, World War II ended, and C.M. and her family had to leave the city immediately. Although they had only a small amount of baggage, it was stolen, and they lost all of their belongings, including their clothes, their jewelry, and their family photos. Her husband, who was fluent in English and Chinese, succeeded in negotiating for the family passage on a ship going back to Japan. Recalling this trip, C.M. said, "I was so afraid that I would not return to Japan until I saw the land of Japan." She also remembered that on the ship "the food was dried cod and water. That was it. ... Soon after we landed in Japan, we had a bowl of rice, miso soup and pickles. It was delicious. I still remember that taste." Because of this experience, she has lost all of the photos and other important forms of evidence that could confirm her earlier life events (Fig. 21.9).

The family started their new life in Tokyo. The housing provided by the Ministry of Railways had vegetable gardens. C.M. and other residents of the housing estate cultivated vegetables, such as potatoes and eggplants, to supplement their food supplies. However, people outside of the estate often stole these vegetables because people were struggling to survive under severe food shortages.

C.M.'s husband passed away in 1951 at the age of 55. C.M. and her children then moved into her parents' home. Her son went to Tokyo University, and later received his Ph.D. from the University of Michigan. He became a professor at Toyo University, but passed away at the age of 52 in 1974. We found a book about civil engineering technology that he had published in 1975. C.M.'s daughter's life was also shorter than expected. She died in 1984 at the age of 57.

After the loss of her two beloved children, C.M. lived with one of her grandchildren. She eventually decided to move into a nursing facility, but then came home after failing to adapt to the environment. At the age of 97, she moved to a nursing home again. She participated in the Tokyo centenarian study on July 8th, 2001, when she was 100 years old. At our first visit, she did not need care from others, despite living in a nursing home. Able to move around well with a cane, C.M. was very active, and enjoyed writing haiku poetry and doing calligraphy. She also participated in an intelligence assessment (Fig. 21.8) (Inagaki and Gondo 2003). Compared to other 100-year-old participants, her score was very high, especially for the fluid dimension of intelligence. She was also careful with her diet. Her everyday routine was to drink two liters of water and a half glass of wine, and to eat a lot of fruit. Speaking of her current life, she said, "I am not lonely at all. I do not know 
Fig. 21.9 C.M. was taking an intelligence test on September 23, 2001, at age 100

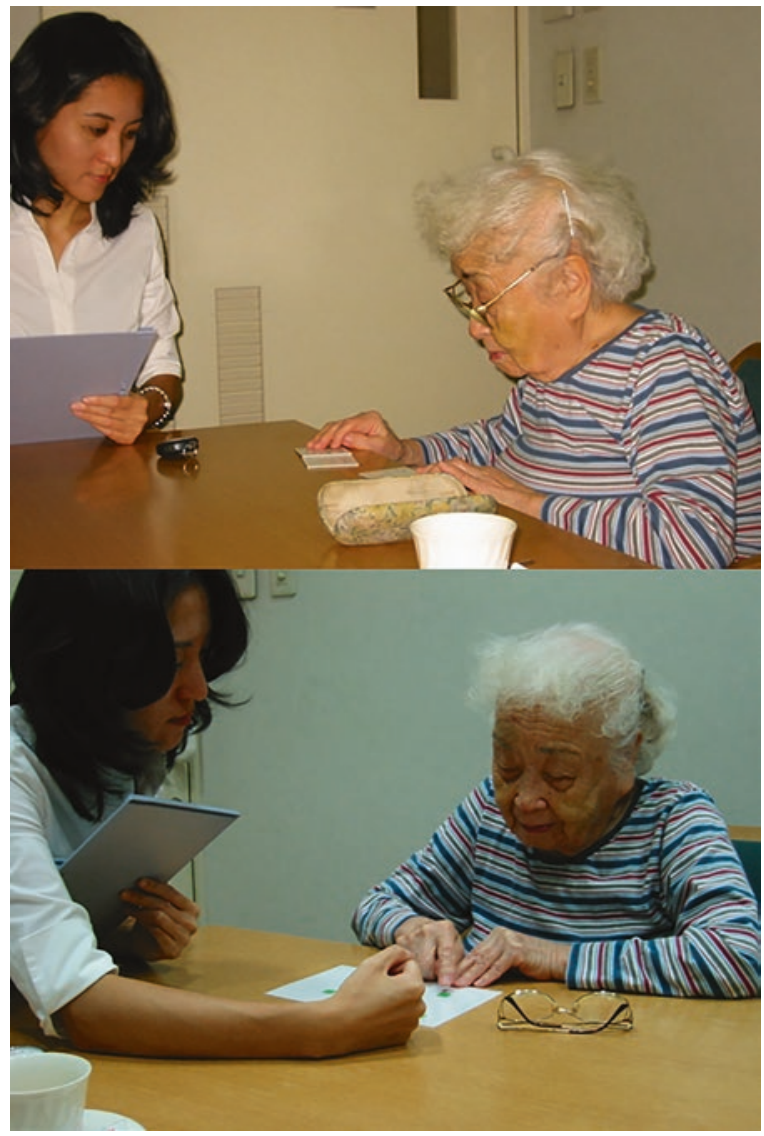

when I will die, but I am always looking forward to seeing my future.” She reported that even as a child she was known for being kind and having a strong will. At the age of 102, she still had a strong will. She said, "I always do the things I want to try. I feel uncomfortable if I do not finish the things I started."

On June 10, 2006, she participated in the Japanese semi-supercentenarian study. At that time, she was living in the same nursing home. Although many residents of her nursing home had developed dementia, she was able to build good relationships with other residents. After her initial participation, we called the nursing home periodically because we would like her to remain involved in our study; however, we lost contact because she relocated. In 2011, we found out that she moved to a nursing home in Yokohama city. We tried to contact her via the Yokohama city government, but we could not reach her.

In the fall of 2015, we found information about C.M. in an article published in Anti-Aging Medicine (Shirasawa 2015). She was interviewed by a famous medical doctor studying longevity. Soon after, on December 5, 2015, she became the secondlongest-living person after Nabi Tajima. We again sent her a letter inviting her to 
participate in our study, and she agreed. At that point we had heard that she was in good health, was having conversations with people, and was doing calligraphy. However, we had to postpone a planned visit after she fell ill.

When one of the authors (N.H.) visited her on May 10, 2016, she was still hospitalized. Her health condition was so serious that we could not communicate with her. He visited her again on October 25, 2016, when she was recovering from a serious condition. At that time, she was wide awake and able to communicate with N.H. He heard that she was experiencing a 3-day cycle in which she was active on the first day, less active on the second day, and asleep for many hours on the third day. Although she had lost both legs because of arteriosclerosis and she was using a gastrostomy-feeding tube, she said that she wanted to go back to the telegraph station to work once she recovered.

\subsection{Summary}

The aim of this chapter was to present the life histories of three Japanese supercentenarians who reached the age of 115 years, and to explain the methods we used to verify their ages. Three cases were described. We were able to collect a large number of official and non-official documents for J.K., but less information for M.O. and C.M. The availability of documents for the age verification of centenarians depends on three conditions: whether the person moved away from his/her birthplace, whether the person lived in a rural or an urban area, and whether the person is a man or a woman.

As we described above, M.O. and C.M. had moved away from their birthplace, married into their partner's family, relocated several times, and lived in the downtowns of big cities. Frequent changes of status can make tracing the life of an individual difficult, and may cause the records of individuals to be switched (Wilmoth and Lundstrom 1996). In Japan, women tend to move their KOSEKI from their original family to their husband's family (C.M. and, presumably, M.O did this for a period of time), or they establish a new KOSEKI for some reason (M.O.). After a woman has moved her KOSEKI from her original family to her new family, it generally becomes unimportant to her and to her offspring, except if they are involved in a court case to negotiate property succession. Therefore, the woman and her children and grandchildren tend to lose interest in their origins, and gradually disconnect from their original family members. In such cases, the offspring of a woman centenarian may not be able to access the original KOSEKI that contains information about the woman's parents and siblings.

As this chapter has shown, these kinds of difficulties have arisen in our survey. In addition, having lived in big cities (C.M. and M.O.) or having been repatriated after WWII (C. M.) increases the risk that a centenarian will have lost important documents needed to prove his/her identity. In these cases, it is difficult to find evidence to verify the person's age. Various kinds of interference can have a negative impact on the age verification process in Japan. The case of J.K. is exceptional for being 
affected by none of these interfering factors. Although the resources available for age verification differ across cases, the reported ages of the individuals profiled in this chapter were found to be accurate. We could show consistency in their life histories based on the testimonies of the centenarian themselves, their relatives, their care workers, media reports, and official documents.

Finally, we should mention the importance of taking into account changes in the testimonies made by a single individual, and discrepancies in the evidence provided in other testimonies and records. In the case of M.O., two different stories were told about the elementary school she attended: one source (the nursing home record) reported that she went to elementary school in the Temma area where she was born; while another source (testimony by her son) reported that she went to school in Takarazuka city where she grew up. We selected the latter report because M.O. herself mentioned that she attended elementary school in Takarazuka, and because her son recalled that M.O. pointed out the house she used to live in as a child when visting Takarazuka with her family to watch the Takarazuka Revue. In the case of C.M., her account of her marriage changed between interviews that took place 14 years apart. Even in the case of J.K., he said he believed that the earlier date of birth was the correct one.

When verifying the age of an extremely old person, the careful examination of the centenarian's life history by double- or even triple-checking the evidence is essential. Consequently, to verify the age of a supercentenarian, it is necessary to check both face validity, which involves confirming the plausibility of an individual's life history based on official and non-official documents; and concurrent validity, which entails checking the identity of the target individual by cross-referencing life episodes told by the individual with historical or official records (Gondo et.al. 2017).

\section{References}

Arai, Y., et al. (2014). Physical independence and mortality at the extreme limit of life span: Supercentenarians study in Japan. Journals of Gerontology Series A: Biological Sciences and Medical Sciences, 69(4), 486-494.

Centenarian Study Group. (2003). Hyakusai hyakuwa [Hundred stories of centenarian]. Tokyo: Nittoshoin.

Gondo, Y., et al. (2006). Functional status of centenarians in Tokyo, Japan: Developing better phenotypes of exceptional longevity. The Journals of Gerontology Series A: Biological Sciences and Medical Sciences, 61(3), 305-310.

Gondo, Y., Hirose, N., Yasumoto, S., Arai, Y., \& Saito, Y. (2017). Age verification of the longest lived man in the world. Experimental Gerontology, 99, 7-17.

Inagaki, H., \& Gondo, Y. (2003). Biomecanism of centenarian functional dimension and successful aging. Journal of Biomeganism, 27(1), 18-19.

Kimura, J. (2002). Kofukunaru hyakugonen wokaerimite [Looking back of my happy 105 years]. Tango-cho: Ama no hasidate. 
Saito, Y., Yong, V., \& Robine, J.-M. (2012). The mystery of Japan's missing centenarians explained. Demographic Research, 26, 239-252. https://doi.org/10.4054/ DemRes.2012.26.11.

Shirasawa, T. (2015). Hyogiin Shirasawa Takuji no "Hyakujusya ni kike! Choju no hiketsu" Oishii syokuji to wain de siawase raifu Miyako Chiyo san [Councilor Takuji Shirasawa's "Ask centenarians about longevity mystery!" Happy life with delicious meals and wine; Mrs. Chiyo Miyako]. Anti-Aging Medicine, 11(5), 644-647.

Wilmoth, J., \& Lundstrom, H. (1996). Extreme longevity in five countries: Presentation of trends with special attention to issues of data quality. European Journal of Population, 12(1), 63-93.

Open Access This chapter is licensed under the terms of the Creative Commons Attribution 4.0 International License (http://creativecommons.org/licenses/by/4.0/), which permits use, sharing, adaptation, distribution and reproduction in any medium or format, as long as you give appropriate credit to the original author(s) and the source, provide a link to the Creative Commons license and indicate if changes were made.

The images or other third party material in this chapter are included in the chapter's Creative Commons license, unless indicated otherwise in a credit line to the material. If material is not included in the chapter's Creative Commons license and your intended use is not permitted by statutory regulation or exceeds the permitted use, you will need to obtain permission directly from the copyright holder. 